\title{
Synthesis and Characterization of Iron Oxide Particles for Medical Applications
}

\author{
M. KISHIMOTO ${ }^{\text {a) }}$, A. SEKI ${ }^{\text {a) }}$, A. HORIUCHI ${ }^{\text {a) }}$, R. MIYAMOTO ${ }^{\text {() }}$, T. ODA ${ }^{\text {b) }}$, H. YANAGIHARA ${ }^{\text {a) }}$, and E. KITA ${ }^{\text {a) }}$ \\ a) Institute of Applied Physics, University of Tsukuba, Tsukuba, Ibaraki 305-8573, Japan
}

b) Department of Surgery, Faculty of medicine, University of Tsukuba, Tsukuba, Ibaraki 305-8573, Japan

\begin{abstract}
Two kinds of iron oxide particles -spherical cobalt-containing iron oxide particles with spinel structure and platelet $\gamma$ - $\mathrm{Fe}_{2} \mathrm{O}_{3}$ particleswere synthesized for medical applications. The particle size of the spherical cobalt-containing iron oxide particles was about $20 \mathrm{~nm}$ regardless of the coercive force that was varied in the range of about 4.0 to $39.0 \mathrm{kA} / \mathrm{m}$ by varying the Co content. The size and coercive forces of the platelet $\gamma-\mathrm{Fe}_{2} \mathrm{O}_{3}$ particles were in the range of about 30 to $100 \mathrm{~nm}$ and about 7.6 to $13.5 \mathrm{kA} / \mathrm{m}$, respectively. The temperature-raising properties were evaluated for water dispersion of these particles under different AC magnetic fields and frequencies to apply hyperthermia or thermoablation using hysteresis-loss heating of ferrimagnetic particles. Heat generation in spherical cobalt-containing iron oxide particles was based on both hysteresis-loss and Brownian relaxation. Platelet $\gamma-\mathrm{Fe}_{2} \mathrm{O}_{3}$ particles showed heat generation completely based on hysteresis- loss.
\end{abstract}

Key Words: Platelet $\gamma-\mathrm{Fe}_{2} \mathrm{O}_{3}, \alpha-\mathrm{FeOOH}$, Coercive force, Hyperthermia, Specific loss power

\section{INTRODUCTION}

Magnetic hyperthermia or thermoablation using small magnetic particles is a new approach for the non-surgical application of heat to cancerous tumors. Much related research has been carried out using magnetic fluids consisting of superparamagnetic iron oxide particles [1-3]. Hysteresis-loss heating with fine ferromagnetic or ferrimagnetic particles is not constrained by requirements such as accurate particle size or driving frequency, which are essential parameters in case of magnetic fluids consisting of superparamagnetic iron oxide particles [4]. To use hysteresis-loss, it is essential to apply a high magnetic field equivalent to that applied in superparamagnetic relaxation systems. There are few reports on hyperthermia or thermoablation that study the application of the hysteresis-loss heating of ferromagnetic or ferrimagnetic particles [5-7].

We prepared spinel-structured spherical cobalt-containing iron oxide particles that have a size of around $20 \mathrm{~nm}[8,9]$ and platelet $\gamma-\mathrm{Fe}_{2} \mathrm{O}_{3}$ particles that have a size of less than $100 \mathrm{~nm}$ [10] for medical applications. In this paper, we report the synthesis and characterization of these particles with different coercive forces and particle sizes. The mechanism of heat generation in these particles was discussed on the basis of the dependency of specific loss power (SLP) on magnetic field and frequency to apply the particles for hyperthermia or thermoablation using hysteresis-loss heating.

\section{EXPERIMENTAL PROCEDURES}

\section{A. Synthesis of Spherical Cobalt-Containing Iron Oxide and Platelet $\gamma-\mathrm{Fe}_{2} \mathrm{O}_{3}$ Particles}

Cobalt-containing iron oxide particles with spinel structure were prepared by co-precipitation of $\mathrm{Co}^{2+}, \mathrm{Fe}^{2+}$, and $\mathrm{Fe}^{3+}$ ions in alkaline solutions. The solution of the metal ions was mixed by stirring with an $\mathrm{NH}_{3}$ solution. The precipitate was then hydrothermally treated at $130{ }^{\circ} \mathrm{C}$ for $2 \mathrm{~h}$ using an autoclave to grow spherical particles with the composition of $\mathrm{Co}_{\delta} \mathrm{Fe}_{3-\delta} \mathrm{O}_{4}$. The coercive forces of particles were adjusted by varying the Co content.

Platelet $\gamma-\mathrm{Fe}_{2} \mathrm{O}_{3}$ particles were prepared as follows [11]: $\mathrm{Fe}^{3+}$ ions were precipitated in an alkaline solution containing sodium hydroxide and ethanolamine, following which it was hydrothermally treated at $130-180{ }^{\circ} \mathrm{C}$ for $2 \mathrm{~h}$ to grow $\alpha$-FeOOH particles. Ethanolamine was added to control the crystal growth of the $\alpha$-FeOOH particles. The size of a-FeOOH particles was mainly controlled by changing the precipitation temperature in the range of about $5{ }^{\circ} \mathrm{C}$ to $-3{ }^{\circ} \mathrm{C}$. After the $\alpha$-FeOOH particles were coated with $\mathrm{SiO}_{2}$ to prevent sintering during thermal treatment, the $\alpha-\mathrm{FeOOH}$ particles were converted to $\gamma-\mathrm{Fe}_{2} \mathrm{O}_{3}$ through dehydration in air, reduction in $\mathrm{H}_{2}$ gas, and subsequent oxidation in air. To examine the temperature-raising properties, water dispersions of these particles were prepared with a silane coupling agent as a dispersant using a sonicator. 


\section{B. Measurements}

The shapes of the spherical cobalt-containing iron oxide, platelet $\alpha-\mathrm{FeOOH}$ and platelet $\gamma-\mathrm{Fe}_{2} \mathrm{O}_{3}$ particles were observed using TEM. The coercive force $(\mathrm{Hc})$ and the saturation magnetization $(\mathrm{Ms})$ were measured for dried particle samples using a vibrating sample magnetometer (VSM) under a maximum magnetic field of $1035 \mathrm{kA} / \mathrm{m}$.

The temperature-raising properties of the particles were examined using the water dispersions, by using a high-frequency magnetic field applicator and by changing the frequencies in the range of 117 to $429 \mathrm{kHz}$ at the peak magnetic fields of $39.8 \mathrm{kA} / \mathrm{m}$. Temperature increase versus time was recorded with a fiber-optic thermometer, at intervals of $1 \mathrm{~s}$. For liquid dispersion samples, SLP, $Q_{F}$, was estimated by using equation (1):

$$
\Delta T / t \Delta \cdot\left(m_{F} C_{F}+m_{W} C_{W}\right)=m_{F} Q_{F}
$$

where $\Delta T / t \Delta, \mathrm{m}$, and $C$ denote the ratio of increase in temperature, mass, and unit mass heat capacity, respectively. Suffixes $F$ and $W$ denote a ferromagnetic material part and water, respectively. The SLP was obtained from the maximum value of $\Delta T / t \Delta[10]$.

\section{RESULTS and DISCUSSION}

\section{A. Shape and Magnetic Properties of Spherical Cobalt-Containing Iron Oxide and Platelet $\gamma-\mathrm{Fe}_{2} \mathrm{O}_{3}$ Particles}

Fig. 1 shows the TEM photograph of spherical cobalt-containing iron oxide particles with Hc of about $23.9 \mathrm{kA} / \mathrm{m}$. The particle size was about $20 \mathrm{~nm}$ and was nearly constant regardless of $\mathrm{Hc}$ in the range of 4.0 to $39.0 \mathrm{kA} / \mathrm{m}$. XRD showed the particles to be spinel- structured $\mathrm{Fe}_{3} \mathrm{O}_{4}$. Fig. 2 shows the relationship between the Co content and $\mathrm{Hc}$ of the particles. There was a linear relationship between the Co content and Hc. This means that the Hc can be controlled by adjusting the Co content. The Ms of the particles was in the range of about 76 to $80 \mathrm{Am}^{2} / \mathrm{kg}$ for the Co content of 2 to 7 at $\%$.

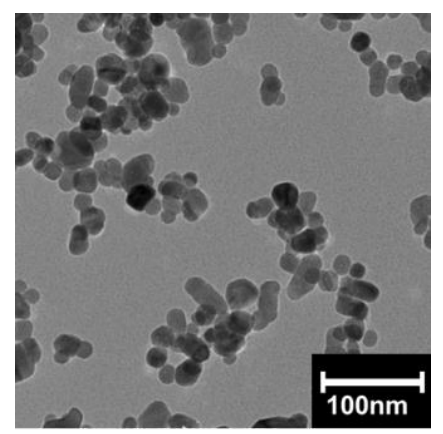

F1g. 1 TEM photograph of cobalt-containing iron oxide particles.

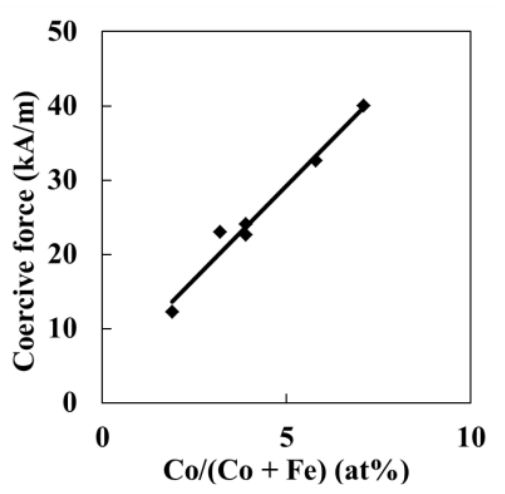

Fig. 2 Relationship between coercive force and cobalt content in cobalt-containing iron oxide particles.

Figs. 3(a)-(c) show TEM photographs of $\alpha$-FeOOH particles synthesized at different precipitation temperatures of 4.8 to $-3.3{ }^{\circ} \mathrm{C}$. The size of $\alpha-\mathrm{FeOOH}$ was reduced on lowering the precipitation temperature and was more affected by the precipitation temperature than by the hydrothermal treating temperature and time.
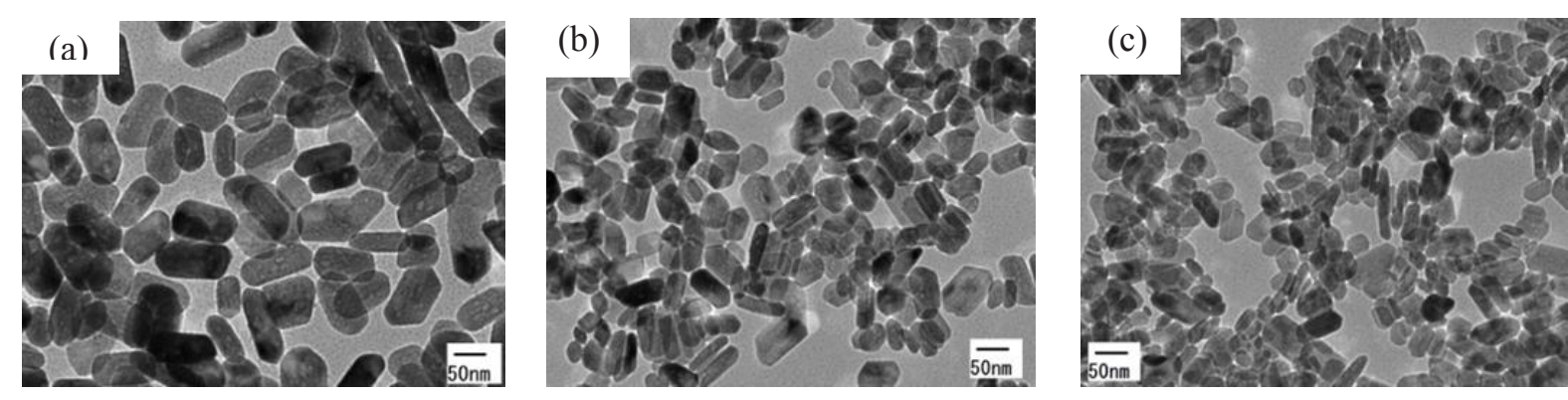

Fig. 3 TEM photographs of $\alpha-\mathrm{FeOOH}$ particles when the precipitation temperature was (a) $4.8^{\circ} \mathrm{C}$, (b) $-1.5^{\circ} \mathrm{C}$, and (c) $-3.3{ }^{\circ} \mathrm{C}$, respectively. 
Figs. 4(a)-(c) show TEM photographs of the $\gamma-\mathrm{Fe}_{2} \mathrm{O}_{3}$ particles obtained from the $\alpha$-FeOOH particles shown in Figs. $3(\mathrm{a})-(\mathrm{c})$, respectively. Dimples formed in the dehydration process were clearly observed in $\gamma-\mathrm{Fe}_{2} \mathrm{O}_{3}$ particles, although they maintained the external form of $\alpha-\mathrm{FeOOH}$ particles. Fig. 5 shows the relationship between the Hc and Ms of the $\gamma-\mathrm{Fe}_{2} \mathrm{O}_{3}$ particles having different particle sizes. The $\mathrm{Hc}$ of the $\gamma-\mathrm{Fe}_{2} \mathrm{O}_{3}$ particles was in the range of 7.6 to $13.5 \mathrm{kA} / \mathrm{m}$, and decreased with their sizes.
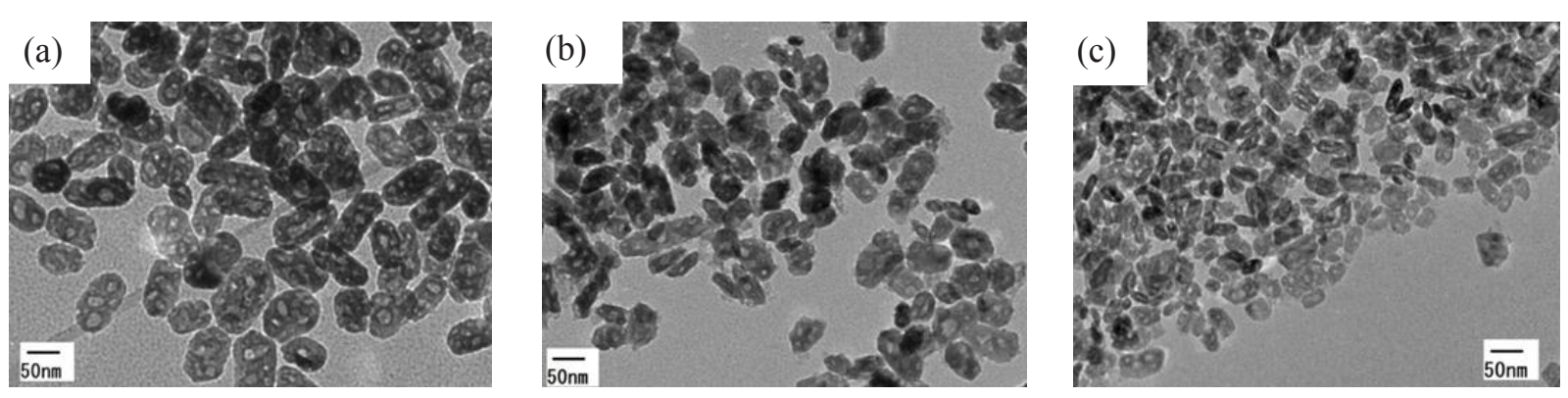

Fig. 4 TEM photographs of $\gamma-\mathrm{Fe}_{2} \mathrm{O}_{3}$ particles obtained from $\alpha$-FeOOH particles when the precipitation temperature was (a) $4.8^{\circ} \mathrm{C}$, (b) $-1.5^{\circ} \mathrm{C}$, and (c) $-3.3^{\circ} \mathrm{C}$, respectively.

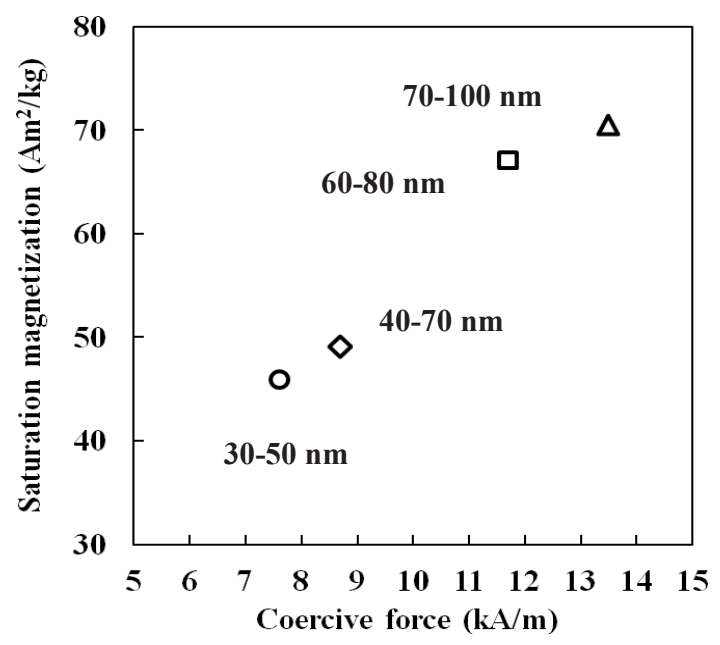

Fig. 5 Relationship between coercive force and saturation magnetization in $\gamma-\mathrm{Fe}_{2} \mathrm{O}_{3}$ particles having different particle sizes.

\section{B. Temperature-Raising Properties and Specific Loss Power}

Temperature-raising properties were evaluated by measuring the rate of increase of temperature of water dispersions containing $0.90 \mathrm{wt} \%$ of platelet $\gamma-\mathrm{Fe}_{2} \mathrm{O}_{3}$ particles. Fig. 6 shows the temperature-raising properties measured for the water dispersion of $\gamma-\mathrm{Fe} 2 \mathrm{O} 3$ particles with the $\mathrm{Hc}$ of $12.2 \mathrm{kA} / \mathrm{m}$ and an Ms of $56.6 \mathrm{Am} 2 / \mathrm{g}$ at the frequency range of 125 to 429 $\mathrm{kHz}$ under a peak magnetic field of $39.8 \mathrm{kA} / \mathrm{m}$.

Fig. 7 shows the SLP plotted as a function of the product $\mathrm{fH}_{0}$ of frequency and magnetic field based on the temperature-raising property shown in Fig. 6. The SLP was compared with those of spherical cobalt-containing iron oxide particles with the $\mathrm{Hc}$ of $11.9 \mathrm{kA} / \mathrm{m}$. The SLP in the spherical cobalt-containing iron oxide particles showed the tendency to saturate at the product of frequency and magnetic field of about $8000 \mathrm{~Hz} \cdot \mathrm{MA} / \mathrm{m}$. This suggested that the heat generation in the spherical cobalt-contained iron oxide particles was based not only on the hysteresis- loss but the Brownian relaxation. The SLP in the platelet $\gamma-\mathrm{Fe}_{2} \mathrm{O}_{3}$ particles linearly increased with increasing $\mathrm{f} \cdot \mathrm{H}_{0}$. This showed that the heat generation in the platelet $\gamma-\mathrm{Fe}_{2} \mathrm{O}_{3}$ particles was completely based on the hysteresis- loss. 


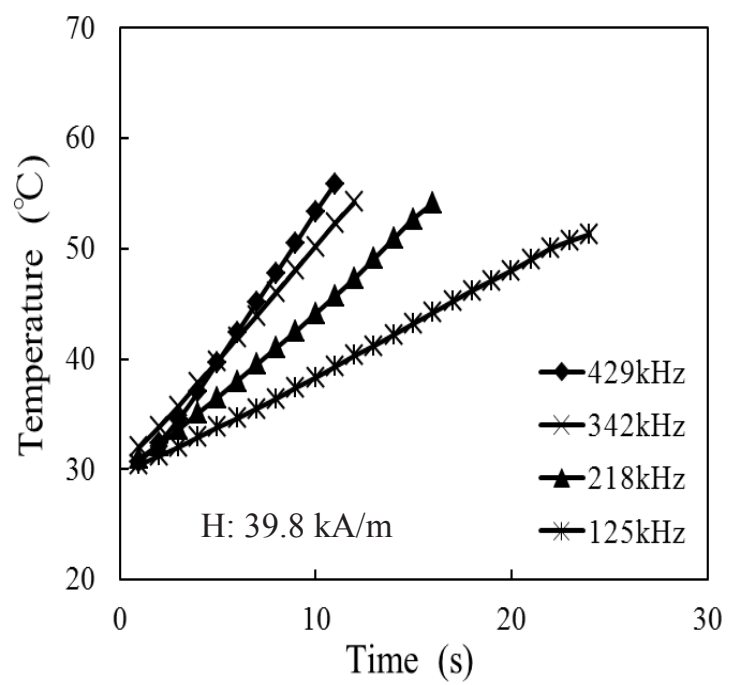

Fig. 6 Temperature-raising properties measured for the water dispersion of platelet $\gamma-\mathrm{Fe}_{2} \mathrm{O}_{3}$ particles under different frequencies.

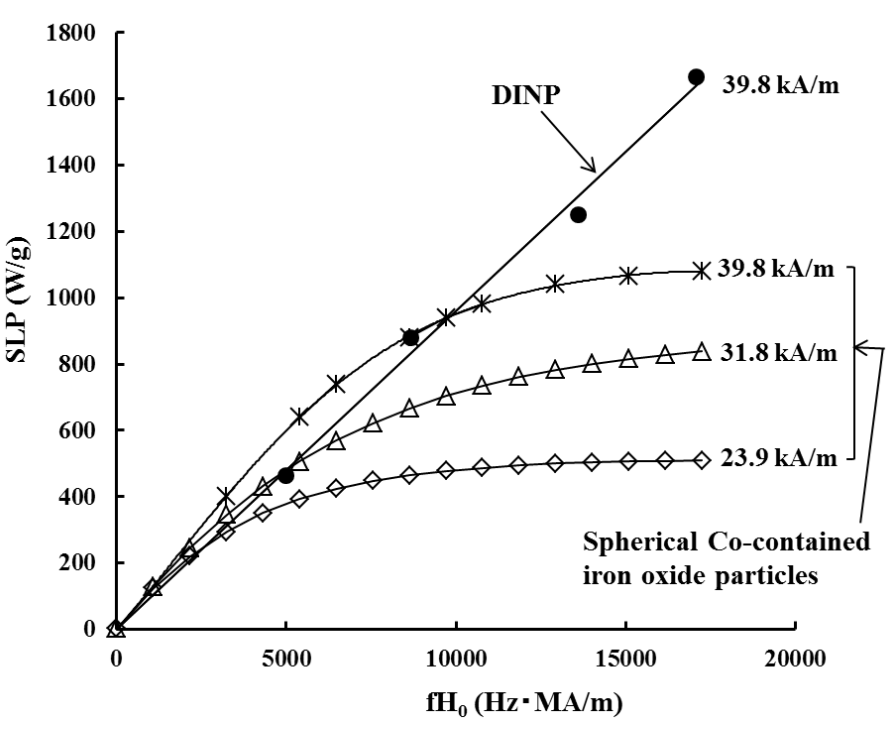

Fig. 7 SLP plotted as a function of the product $\mathrm{f} \cdot \mathrm{H}_{0}$ of frequency and magnetic field in platelet $\gamma-\mathrm{Fe}_{2} \mathrm{O}_{3}$ particles and spherical cobalt-containing iron oxide particles.

\section{CONCLUSIONS}

Spherical cobalt-containing iron oxide particles and platelet $\gamma-\mathrm{Fe}_{2} \mathrm{O}_{3}$ particles with different coercive forces and particle sizes were synthesized for application in magnetic hyperthermia or thermoablation using hysteresis-loss heating of ferrimagnetic particles. Specific loss power was obtained from temperature-raising properties of water dispersions of these particles under different frequencies. Heat generation in spherical cobalt-containing iron oxide particles was based on both hysteresis- loss and Brown relaxation. Platelet $\gamma-\mathrm{Fe}_{2} \mathrm{O}_{3}$ particles showed heat generation completely based on hysteresis- loss.

\section{ACKNOWLEDGMENTS}

This work was supported by Grants-in-Aid for Scientific Research (Grant Nos. 23300185 and 23300362) from the Ministry of Education, Culture, Sports, Science and Technology of Japan.

\section{REFERENCES}

[1] R. Hergt et al., (Eds.), "Magnetism in Medicine: A Handbook”, 2nd ed., Chap.4.6, Wiley-VCH, Weinheim, 2007, p. 550.

[2] R.E.Rosensweig, J. Magn. Magn. Mater. 252, 370 (2002).

[3] J.-P. Fortin, C. Wilhelm, J. Servais, C. Menagera, J.-C. Bacri, F. Gazeau, J. Am. Chem. Soc. 129, 2628 (2007).

[4] M. A. Gonzalez-Fernandez, T.E. Torres, M. Andrés-Vergés, R. Costo, P. de la Presa, C.J. Serna, et al., J. Solid State Chem. 182, 2779 (2009).

[5] D. E. Bordelon, C. Cornejo, C. Grüttner, F. Westphal, T. L. DeWeese, and R. Ivkov, J. Appl. Phys. 109, 124904 (2011).

[6] L. M. Lacrios, R. B. Malaki, J. Carrey, S. Lachaize, M. Respaud, G. F. Goya, et al., J. Appl. Phys. 105, 023911-1 (2009).

[7] B. Mehdaoui, A. Meffre, L.-M. Lacroix, J. Carrey, S. Lachaize, M. Gougeon, et al., J. Magn. Magn. Mater. 322, L49 (2010).

[8] E. Kita, H. Yanagihara, S. Hashimoto, K. Yamada, T. Oda, M. Kishimoto, et al., IEEE Trans. Magn. 44, 4452 (2008).

[9] E. Kita, Shinji Hashimoto, Takeru Kayano, Makoto Minagawa, Hideto Yanagihara, Mikio Kishimoto, et al., J. Appl. Phys. 107, 09B321 (2010).

[10] M.Kishimoto, M. Minagawa, H. Yanagihara, T. Oda, N. Ohkochi, E. Kita, J. Magn. Magn. Mater. 324, 1285 (2012).

[11] M. Kishimoto, T. Oda, Y. Ohara, R. Miyamoto, Y. Akashi, H. Yanagihara, et al., Mater. Trans. 53, 1711 (2012). 